\title{
Affective Atmospheres of Sexualized Hate Among Youth Online: A Contribution to Bullying and Cyberbullying Research on Social Atmosphere
}

\author{
Kim R. Sylwander ${ }^{1}$ (D) \\ Published online: 11 November 2019 \\ (C) The Author(s) 2019
}

\begin{abstract}
In this study, I will introduce the concept of affective atmospheres previously developed by Anderson (Emot Space Soc 2:77-81, 2009) and Anderson and Ash (2015), to explore young social media users' articulated experiences of aggressive behaviour on a popular social networking site in Sweden. This concept opens up for inquiring into bullying, and other aggressive behaviour, as encounters, not only between humans, but also with non-human bodies, and the potentialities to act and the affective states that such meetings enable. In this way the paper contributes to bullying research on school climate and social atmosphere. The paper applies an affect theory approach to atmosphere to explore the importance of different materialities for the production of feelings and emotions surrounding the everyday articulations of hate among these users. The findings suggest that hate, in this context, works through a sexualized and gendered affective regime, which enforces a chrononormative logic, through which temporalized norms are tied to notions of age and bodily growth, that is, through heteronormative expectations of femininity, masculinity, sexuality and age-appropriateness. I found that affordances such as anonymity facilitated and intensified the circulation of hate, feeding into an atmosphere of constant risk. However, I also detail how affordances such as anonymity and hyperlinking, and practices such as hashtagging, enabled expressions of friendship, love and support, thus counter-balancing an atmosphere of hate and enabling it to become bearable for certain targeted users. In this context, sexualized aggression is normalized and expected, but nonetheless also troubled and resisted by these young users. By applying the concept of atmosphere, the paper sheds light on the affective workings within social online settings that become saturated with sexualized and aggressive practices, where certain users become repeated targets of such practices.
\end{abstract}

Keywords cyberbullying $\cdot$ online hate $\cdot$ sexualized aggression $\cdot$ atmosphere $\cdot$ affect

\section{Introduction}

Affect is traditionally addressed as negative psychological consequences of bullying, and cyberbullying, such as feeling stress, fear, sadness, having suicidal ideations or suffering from depression (e.g. Gini and Pozzoli 2009; Hinduja and Patchin 2010; Holt et al. 2015). These psychosomatic effects may have short-term and long-term outcomes for bullying victims (Hinduja and Patchin 2012). Bullying research thus typically places feelings within the individual as an intra-psychological (as well as pathological) state that the individual possesses. In

Kim R. Sylwander

kim.ringmar.sylwander@buv.su.se

1 Department of Child and Youth Studies, Stockholm University, Frescati Hagväg 24, 11419 Stockholm, Sweden this paper, I rather understand affect not only as a bodily state but also as something between bodies, as affective atmospheres (Anderson 2009; Anderson and Ash 2015). This concept opens up for inquiring into bullying, and other aggressive behaviour, as encounters, not only between humans, but also with nonhuman bodies, and to explore the potentialities to act and the affective states that such meetings enable.

While not applying the term, some research identifies the role of "climate" and "atmosphere" in bullying. For instance, Lawrence (1998) describes school climate as the "social atmosphere of a learning environment" or the "“feel' of the school as perceived by students and teachers" (in Hinduja and Patchin 2012, p. 21). Negative school climate has been found to be the effect of violence and bullying, having an impact not only on students' feelings and sense of security in school, but also on their school performances (Hinduja and Patchin 2012; Lee 2005). Positive school climate, conversely, acts to protect against 
violence and bullying within the school as well as among school peers online (Hinduja and Patchin 2012; Loukas et al. 2006; Loukas and Robinson 2004). It has also been argued that spatial aspects of the school architecture and spatial geography affect the prevalence of violence and bullying in schools, as violence seems to be more prevalent in certain school spaces, such as toilets, locker rooms, long corridors or far corners of playgrounds (Lambert 1999; Sikhakhane et al. 2018; Vaillancourt et al. 2010). Youth in different settings express feelings of unease in these spaces. When violence and bullying are prevalent, these feelings of unease can permeate the school climate in a general way, affecting those that are targeted as well as those that are not. Violence and bullying in school thereby affect the way that students feel when they are in the school space, and these feelings in turn affect schools' social atmospheres.

In this paper, I argue for the importance of theorizing atmospheres further when studying peer-to-peer violence and bullying, by exploring aggression among youth on a popular social networking site (SNS) in Sweden in terms of affective atmospheres. My analysis details users' articulations of feelings surrounding posts that they identify as online hate, to explore how aggressive online atmospheres are felt and produced (Anderson and Ash 2015). The findings illustrate the importance of bodies, sexualized materialities (such as clothing, body parts and language) and technological affordances (such as anonymity and hyperlinking) in the production of an online atmosphere of sexualized hate. I will also draw attention to how atmospheres of friendship, love and support are produced as well, enabling the threat of sexualized hate to become bearable for some of the targeted users. Finally, I will discuss how the concept of affective atmospheres can contribute to future cyberbullying and bullying research more broadly, in particular what role it may play in bullying prevention.

\section{Online Hate in the Swedish Context}

In Sweden in the past 10 years, social media usage has increased drastically among children and youth in general, to include users as young as 9-12 years of age (Statens Medieråd $2013 ; 2015$; 2017). Youth express that social media presence is a necessary and taken for granted part of their lives, particularly for girls. In Sweden, nearly all 9-16-year olds have a smartphone and most use them to access social media daily (Statens Medieråd 2017). ${ }^{1}$ While academic literature use concepts such as (online) hate speech (Gagliardone et al. 2015) or cyberbullying (Livingstone and Smith 2014), the youth in this study used the term hate to identify problematic or contentious encounters online, however hate or online hate (Swe: 'hat' or

\footnotetext{
${ }^{1}$ Among 9-12-year olds, 58\%, and 13-16-year olds, 90\%, use their smartphones to access social media.
}

'näthat') are also widely popularized terms in Sweden more generally. ${ }^{2}$ Since the institution of the web 2.0 , the term online hate has increasingly been used by media and policy makers and national authorities to describe a broad phenomenon encompassing everything from racist and sexist hate speech, to meanness, harassment and bullying in the online context (Statens Medieråd 2017). The past few years, public concern has turned to sexist and sexual harassment of women and girls online, culminating in the \#metoo movement. Young internet users also report that gender (including non-normative gender expression), sexuality and ethnicity (Friends 2017, 2018) are the most common targets of bullying and aggression in school and online. Girls and boys alike report experiencing pressure based on strict gender norms regarding their appearance and behaviour (Friends 2018; Svensson and Dahlstrand 2013) online as well as offline. This echoes research findings in other countries that has found that youths' experiences of aggression online is greatly impacted by expectations of white middle-class heteronormativity (Crooks 2017; Ringrose and Harvey 2015).

In the Swedish context, as elsewhere, certain platforms are infamous for the spreading of hate and aggressive online behaviour. On popular online gaming platforms among youth in Sweden, such as Minecraft, World of Warcraft and Fortnite, misogynous and bigoted practices are considered normal (see also Cook et al. 2016). Similarly, social media platforms such as Instagram, YouTube and Snapchat, are known to be saturated with negative content and mean practices but nonetheless remain the most popular SNSs among young users in Sweden (Friends 2017; Statens Medieråd, 2017). Teens indicate that their experiences of harassment online are closely related to the negative jargon that pervades certain online spaces. They point out that in spaces where negativity and meanness is common, such acts may pass as normal and as a taken-for-granted part of the online climate (Friends 2017).

\section{Affective Atmosphere, Circulation and Normative Online Aggression}

I understand affect as the capacity to affect and be affected by others (Massumi 1995). This implies that affect is not simply an affective state or feeling that we possess in our bodies but a relation between human and non-human bodies. To emphasize the spatial and collective dimensions of affect, I use the term affective atmosphere, as it is understood as articulated through the feelings and senses a person experiences of a place upon entering it and inhabiting it (Anderson 2009). Atmosphere, like climate or weather, envelopes those inhabiting them and affects how they feel and experience a place, like a "thickness in the air" (Ahmed, 2004/2014, p. 22).

\footnotetext{
${ }^{2}$ Swe: 'hat', or 'näthat'; translated to hate or online hate.
} 
Staff and students entering a school with a negative social climate may therefore feel this as they enter the premises (Hinduja and Patchin 2012). Atmospheres have a collective quality in how they are experienced and transmitted between people, as common moods or ambiances (Gottzén and Sandberg 2017), but they are also diffuse, indeterminate and constantly evolving (Anderson and Ash 2015). An atmosphere is thereby "at once a condition and conditioned" (Anderson and Ash 2015, p. 35) and at once "transpersonal and prepersonal" (Anderson 2009, p. 78). Atmospheres are picked up differently by different (human) bodies, and different bodies are expected to affect the atmosphere differently. The way, for example, the teacher will affect the atmosphere in a classroom upon entering, a student entering would normally not have the same effect. In a strained atmosphere, one might search for an explanation and someone might "become the cause of that tension" (Ahmed, 2004/2014, p. 227). When this explanation "takes hold" then specific emotions are directed towards that which is deemed to be the "cause of the tension" (p. 227). Atmospheres are not only affected by (and affect) human bodies, but are also affected by materiality and design, what purpose that space is expected to have and what objects can be found in that space. For instance, the waiting room of a hospital and the objects in that space, like an aquarium, will impact how bodies act and feel in that particular space (Anderson and Ash 2015). It is important therefore, when trying to understand aggressive atmospheres, to study the relationality between materialities (e.g. bodies, clothes, technology) and experiences of aggressive behaviour and how, in turn, this affects how a space is felt. In the following section, I will discuss how online atmospheres are shaped by the flow of affect online and how the design and functionality of online spaces enables communicative flow and particular atmospheres of hate and misogyny.

Online communication is multi-layered, often involving huge numbers of participants (as discussants, as readers, as administrators, etc.) and involving different types of interaction and communication. As the negative affect moves and "sticks" (Ahmed, 2004) to materialities and bodies in contentious online interactions, it intensifies, becomes volatile and violent (Kofoed 2014; Kuntsman 2012; Paasonen 2015; Sundén and Paasonen 2018). This often plays out in spaces like online discussion boards, social media or in online games, where discussions very quickly become heated and aggressive. This intensification of affect may alter the atmosphere and work to limit the capacities of certain users in certain contexts, for example those that have been targeted or have been the point of contention in a particularly heated online debate.

The normative aspects of how intensification unfolds in online interaction is closely related to how bodies and signs are understood and felt in given contexts but also how bodies feel upon entering those contexts. How an atmosphere is picked up by an entering body "is always felt from a specific point"
(Ahmed 2010, p. 41). This point of entry is shaped by the history of a body (for example gender, sexuality, race), the history of a body in a specific context, the feelings and expectations which that body carries into the space as it enters and subsequently the effect that body has on other bodies and objects in that space. The concept of "sticking" describes "an effect of the histories of context between bodies, objects, and signs" (Ahmed, 2004/2014, p. 90). This was the case in the present study, as the youth generally used their offline identities in their online profiles. Therefore, their online profiles were (to a certain extent) a representation of their offline selves, including their gender and age. About $63 \%$ of the youth identified as female and much of the interaction was oriented around these girls, their bodies, their comportment, sexuality, class and race. Their bodies therefore entered the online space from a specific vantage point, impacting the way they were "felt" by others and how they themselves experienced the atmosphere online. This specific vantage point is important in regard to the online space, particularly considering that users must write themselves "into being" (Boyd 2006).

The affective sticking online is central to understand how certain practices become dominant in online spaces and thus how they are felt as atmospheres. Girls' different body parts, such as "boobs", are often sexualized and used to subjectify, injure and police (Kofoed and Ringrose 2012; Ringrose and Harvey 2015). Girls and boys face different sexualized regulation online where girls are expected, but also punished, for being sexy or sexually active. Whereas boys are celebrated for their sexual endeavours (Sylwander and Gottzén 2019). Sexualized insults such as whore and slut seem common in youths' online conflicts and may affectively work to discipline, control and injure in such a manner that some girls are rendered unviable. Online (as well as offline) life may become temporarily unliveable for them (; cf. Kofoed and Ringrose 2012; Sylwander and Gottzén 2019). Online hate targets and sticks to bodies identified as other (the female, homosexual or racialized body) through shaming and fear to silence, limit and incapacitate bodies that align with othered causes (Mantilla 2013; Sundén and Paasonen 2018). "Stickiness" is thus helpful in understanding how certain bodies become the targets of online hate, and thus how, for certain users the online atmosphere is more saturated with hate than for others.

Studies of online misogyny have drawn attention to these processes by looking at misogynous and aggressive social climates on online discussion forums such as Reddit, 4/chan/b as well as online gaming platforms (Chess and Shaw, 2015; Ging and Siapera 2018; Jane 2017; Phillips 2015; Todd 2015). These studies show how misogynous and derogatory practices are "tolerated, but not encouraged" (Cook et al. 2016, p. 3337). They nonetheless illustrate how users often conform to aggressive gaming cultures and adapt their language to either distance themselves from these practices, to more easily engage in them or to avoid being targeted (McInroy and Mishna 2017; Moor 2007; 
Moor et al. 2010). In such atmospheres of misogyny and aggression, these practices are often seen, by inculcated users, as funny (Phillips 2015), and understood by many as indispensable for the freedom of expression online (Moor et al. 2010).

As noted above, the spatial and material arrangement of a space inevitably affects its atmosphere and how bodies move and act within it. In a school, for instance, the design of classrooms, bathrooms, corridors and playgrounds influence how students move and interact. In turn, this behaviour affects how they feel when they are in these spaces. Aggressive behaviour such as bullying has been found to occur to a higher degree in spaces that, due to the architectural design, are far away from adult supervision (Vaillancourt et al. 2010). The arrangement of a space may thus enable certain encounters and limit others. In the same way as three-dimensional spaces, online spaces are shaped by the potentialities created in their architecture, in other words, the interface design (structure, layout, options, etc.) and affordances (a sites' functionality) of a site. The design of an online platform or website determines what a user can do there and therefore shapes the interaction thereon. For instance, anonymity is pivotal for enabling bullying in the online context where most aggressive online discourse is produced by pseudonymous and anonymous accounts (Barlett and Chew 2016; Brown 2018; Gagliardone et al. 2015; Sticca and Perren 2013). This is theorized to be the result of a loss of inhibition online due to affordances such as the invisibility (afforded by anonymity), asynchronicity (communication does not occur at the same time), and the lack of eye-contact which enables users to express themselves in otherwise frowned upon ways (Lapidot-Lefler and Barak 2012; Suler 2004). Designed elements of a platform may therefore serve to facilitate aggression, but do not necessarily determine them. Thus, online atmospheres are not solely formed by designed elements but these elements are rather part of, and interact with, a variety of elements online (bodies, objects, discourses, etc.). The term affordance is imbued with ambiguous causality as interface design influences user practices and interactions, but as users "make sense" of these elements and put them into practice, they inevitably also affect how these technological and visual aspects are perceived and experienced by others (McVeigh-Schultz and Baym 2015). The atmospheres tied to a users' profile on a site is therefore the contingent product of users' input, site architecture and design, and affective contributions by other users (Paasonen et al. 2015). As users' behaviour and platforms are constantly changing, online atmospheres are not static but rather contextual, subjective and contingent that several atmospheres can coexist on one platform and within a group of interconnected users at the same time, and these are subject to constant and instant change (Anderson and Ash 2015.

\section{Studying Affective Atmospheres}

This study is part of a larger netnographic research project on young social media users' interactions on a social networking site
(SNS) (cf. Kozinets 2015, Murthy 2008). The netnographic fieldwork was conducted over a period of 2 years between 2015 and 2017, through a non-interventionist approach (Kozinets 2015; Markham 2013; Murthy 2008). The fieldwork focused on younger social media users and included the complete body of interaction from the profiles of 150 young users, aged 11-15 years, on a popular public social networking site SNS among Swedish teens at the time. Among the users 95 identified as girls and 53 as boys, 2 identified as non-binary. Girls are much more active on social media in Sweden (Friends 2017; Statens Medieråd, 2017) and so too on this SNS, therefore more profiles belonged to girls. Forty-two users identified as ethnically mixed or as immigrant (Swe: invandrare). As the age limit for establishing a profile was 13 , this meant that the interactions studied included users that were not legally allowed to participate but did so anyway. Users had been active for varying periods, ranging from a few months to at most 3 years at the time of the fieldwork. The study included over 358,391 posts encompassing, written posts, photos, screengrabs, memes, links, online video material and gifs, as well as self-produced video material. All profiles included selfreported information concerning the users' age and gender. At the time of the ethnographic fieldwork, the site chosen was one of the most used public SNSs among youth in Sweden.

The netnographic material was read continuously throughout the ethnographic fieldwork and detailed ethnographic notes were taken in order to be able to continuously identify emergent themes. During the ethnographic fieldwork I found that the word hate emerged as the most common way for contributors to identify problematic or aggressive contributions that they encountered. Thus, posts containing the word hate were used as a starting point to identify relevant excerpts for this particular study. The SNS where the users in this study are interacting had various affordances. Users construct a profile, which is the public space for communication between users. There is also a private messaging function which allows users to communicate with each other directly without being publicly visible to profile visitors. Visitors do not have to have their own account to read profiles or to write comments, and this differentiates the space from other semi-public or private SNSs where users have to have their own profiles and logins to be able to take part. When writing on other profiles or writing direct messages users can choose to be anonymous or to share their hyperlinked pseudonym. ${ }^{3}$ Most users are not anonymous, in other words, they may have a pseudonym but they also divulge their real offline identities in their profiles. However, some users use pseudonyms without divulging their offline identities. Users are able to upload written posts, including features such as emojis, hyperlinking and a like function. Users can also upload photos, gifs and video material, and they can design their profile background using text, images and gifs. The functions of this site

\footnotetext{
${ }^{3}$ Hyperlinking enables a user to click on a user name in a comment to directly access that profile. If users share a link to a website, video or another user's profile, this will also be hyperlinked, and thereby clickable.
} 
and the productive capacities that they are imbued with will be discussed in the analysis to further understand the production of atmospheres of hate. Due to the asynchronous nature of interaction on this SNS as well as the possibility to send private and anonymous messages, it was at times difficult to identify which posts the users thought were hate. Therefore, most of the posts analysed in this study are users' responses to hate.

The following steps were taken when analysing the material. Firstly, all posts which included the word hate (Swe: 'hat', 'hat*) were extracted from the collected profiles using the software program Nvivo. The posts referring to hate in an unrelated or indeterminable manner were then excluded (for example: "I hate McDonald's" and "I hate my hair"). The material was then coded and interactions were mapped (cf. Fox and Alldred 2015). By mapping posts I was able to follow interactions and exchanges between users over several posts and at times over several profiles, thereby contextualizing the framing of hate and related articulations of feelings, emotions and senses, thus following the flow of affect and emotions across user interactions. Recurrent themes were subsequently identified by mapping recurrent articulations of atmosphere.

As prepersonal and transpersonal (Anderson 2009), atmospheres are never fully expressed through verbal or written articulations, as feelings and emotions are complex bodily experiences. However, the practice of naming atmospheres through the articulation of sensations is the manner through which we can access the subjective sense that someone makes of that atmosphere (cf. Anderson and Ash 2015 , p. 36). In order to study atmosphere online I relied on the articulations, depictions and visual representations of bodies, body parts, clothing and objects, rather than the bio-physical materialities themselves. I therefore used available articulations of sensation, emotion and feeling by the users to explore and map how they sensed atmosphere in relation to the naming of hate, and followed these flows in their interaction, by following exchanges and affective flows through various linking practices such as hashtagging and hyperlinking, where possible. To understand atmospheres and how they were affectively produced, it was of particular interest for the analysis to explore instances of atmospheric changes (Anderson and Ash 2015, p. 45) and affective directionality, for instance, what affects such as anger, disgust and fear were directed towards, and what, or who, was fixed as the cause of the "tension" (Ahmed, 2004/2014). In this manner I identified themes through recurrent articulations of affective flow. This resulted in the following themes: (1) an atmosphere of gendered risk, (2) gendered materiality and enforced chrononormativity, (3) anonymous cowards and the embodied threat of anonymity, (4) the affective circularity of sexualized hate, (5) atmospheric shift and troubling the role of the hater and (6) passionate friendship.

\section{Ethical Considerations}

Standards and practices of online research ethics have been drastically redrawn since the start of this project. At the outset of this project, researchers were not in agreement as to the ethical limits concerning the collection of material online (see Markham et al. 2013; Kozinets, 2015). As an ethnographic researcher, an ethically reflexive approach was central in how I went about reading understanding and analysing the online interactions. Firstly, the SNS which was the primary site of my netnographic fieldwork was a public SNS, in other words, anyone could access the interactions and profiles that I visited. Many netnographic researchers have criticized this approach, as it may not be sensitive to the fact that the users may not be aware of the level of publicness of their communication (e.g. Kozinets 2015). In my material, it was evident that most users adopted certain strategies and behaviours on public platforms and others on more private ones, such as direct messaging applications. This included things like discussing private or intimate matters with their friends, or communicating romantically or sexually with others. Most users also created different public and private accounts on various platforms, such as Instagram, demonstrating an awareness and ambition to manage privacy and the disclosure of intimate matters. Nonetheless, users often engaged in personal discussions or described personal experiences on their public profiles as well. As most profiles that are part of this study are no longer in use, many excerpts are no longer searchable, nor identifiable. This minimizes the risk that the material could be unmasked. It is my responsibility and prerogative to protect the integrity of the users. Even though the material I present contains sexualized and, at times, sensitive depictions, I have chosen examples that represent findings that exemplify and illustrate more generalized tendencies within the material. This being said, most excerpts could be exchanged with others from other users, and as such the material should stand the "self-recognition" test. That a user should not be able to identify themselves if they would read the material published. The most sensitive and personal material has thus not been published in this study.

As fieldwork for this study was conducted on a public SNS, one did not require membership, a profile or login in order to access the interactions (Markham et al. 2012; Markham 2013). ${ }^{4}$ The central ethical premise for presenting excerpts was the protection of the individuals through a process of masking the material presented, with special consideration taken to the users' young age. Firstly, the anonymity of the users is protected by not disclosing the particular site where profiles have been collected. Secondly, all identifiable information was decoded to anonymize the users in the excerpts. Thirdly, all excerpts were translated from Swedish to English, so that excerpts are not searchable. Lastly, a reflexive

\footnotetext{
${ }^{4}$ The larger research project, of which this study is part, has been reviewed and approved by the Regional Ethical Review Board in Stockholm, Sweden (dr. no. 2015/510-31/5).
} 
approach to ethics was applied throughout the analysis. Some excerpts were therefore excluded based on their sensitivity or the possibility of identification.

\section{An Atmosphere of Gendered Risk}

As previously mentioned, users identified contentious posts and exchanges by calling them hate. These exchanges centred mainly around a target's gender, sexuality and age, particularly sartorial expression (how they dress and do their make-up/ hair), how developed their bodies were (and thereby how sexual their bodies were perceived to be), how they represented their bodies in pictures, sexual relations and all in relation to temporalized notions of age appropriateness. The users in this study expressed feelings of a constant risk of being targeted by hate, affecting how they behaved.

Sara: $\downarrow$ Put up an ugly picture of yourself $\downarrow$ You are ugly you get hate You are a good person you get hate You are happier than others you get hate you have lots of girls/ guys around you you get hate you have a good life you get hate You are better than others you get hate You are bad at riding a bike you get hate You are fat/thin you get hate You are perfect you get hate You feel bad you get hate You laugh you get hate You laugh you get hate

Sara identifies any position, person, body part, feature, or behaviour as being at risk of becoming a target of hate. Describing a sense of impossibility and frustration at the contradictory nature of idealized behavioural and physical norms. There thus seems to be a constant movement of affects and a sense of risk through a wide range of alternative coded objects - in the form of bodies, attributes and behavioursthat stick together in assemblages that can become targets of hate. This seems to bring about a constant fear of "collapse or potential collapse" as users are uncertain of what may be targeted or who may be targeting them, in other words their control over context is limited (Marwick and Boyd 2011). Even though users expressed feeling a constant risk of being targeted (the way you act, dress, the feelings you express, etc.), they nonetheless went about the everyday business of chatting to friends about how much they like each other, what they are up to, where to meet up, or what brands they like. This may appear somewhat contradictory, but I believe it demonstrates that different affective atmospheres are at play at the same time. These users gravitated towards this SNS as a common space of sociality, all the while facing a pervasive sense of the risk of being targeted by hate in that space. This risk materialized for some users more often than others and for some users it became temporarily unbearable (Kofoed and Ringrose 2012). Melina is such an example. She frequently expressed being victimized but was repeatedly told that it is part of being active on the SNS, and on social media in general, and that if she could not "handle" it she should shut down her profile, or just accept the hate she receives.

Anonymous: Put away your computer then if you can't take a compliment

Melina: I can never take a compliment. Haters have made it impossible for me to take a compliment. People just lie when they give me compliments. $\square$ I am fat, ugly, retarded, a failure etc. ask anybody, I don't look good. I am really ugly. Yuck. [...] why am I so ugly? Cause I was born to be feel bad and be hated, and never to be happy. I will never be like the girls that all the guys want. No not like that. Don't want to be like that. [...] oh well, I don't' have anorexia, I'm not fat, I'm not skinny, I am not normal. Blablabla, I am fat and skinny and everything blablabla, think what you like, I think I'm fat. And sometimes that I am skinny. It depends on the damn comments.

The pervasiveness of hate she receives means that this has become the dominant atmosphere that she experiences when on this SNS (cf. Anderson 2009). In other words, this atmosphere of hate, curtailed her affective capacities, in the sense that it limited her access to certain emotions in connection to her online presence. For instance, it has made it "impossible" for her to take a compliment, or to feel happy ("never happy") or to feel normatively desirable ("I will never be like the girls that all the guys want"). The hate has thus become embodied as far as she expresses a sense of self-disgust ("yuck") and of not being "normal", through which circulated an array of contradictory experiences of outsidedness: "I am fat skinny and everything." Her experiences of hate thus coalesce in a complex circulation of negative affects related to her body in this particular affective atmosphere. These complexities associate the desirability of her body (ugly/not what guys want), the acceptability or non-conformity of her body/corporeal abjectness (anorexic/fat/skinny), and her ableness (retarded/normal) to affective regimes of disgust, hate and fear.

\section{Gendered Materiality and Enforced Chrononormativity}

For the purpose of exploring the intersectionality and affectivity in this context I will draw on Freeman's (2010) concept of chrononormativity. Chrononormativity describes how "naked flesh is bound into socially meaningful embodiment through temporal regulation" (Freeman 2010, p. 3). The term describes how bodies are bound into embodied practices of normative temporality. It is also through such temporal sequencing that 
bodies become culturally and physically legible (Freeman 2007). In this sense, temporality becomes practiced, embodied and felt as "natural" (Freeman 2010). I will read this process of embodiment through the articulations of feeling and emotions that the users make concerning bodies, things and actions in the context of responding to hate. Chrononormativity reflects the manner in which norms such as femininity, masculinity, heterosexuality and class, for instance, are temporally sequenced, felt and affectively practiced. I found that age and sexuality stuck together with understandings of appropriateness of age and sexuality in given contexts and enacted "competing and contradictory sexual assemblages" (Renold and Ringrose 2011, p. 404). A user's desirability (e.g. sexiness, prettiness, dateability, "fuckability") was therefore determined in relation to the perceived age appropriateness of their attire (e.g. g-strings; pushup bra), the way they presented themselves in pictures (e.g. selfies read as too sexy) and physical features (such as breast size) (see also Springgay and Freedman 2010). These signs, objects and body parts thus circulated and were felt by users as temporally acceptable or out of place. Freeman describes how the affective encounter with such disciplining objects can feed both hatred and entitlement when read as "asynchronous" (Freeman 2010, p. 19). Andrea was a popular girl; she had a large following beyond her immediate group of friends and school. There was a lot of discussion concerning the way she dressed, how she did her make-up and how developed her body was. She often received hate directed towards her breasts, saying that they were "too small".

Anonymous: I argue with anyone who says that you are beautiful and nice you look worse than my ass you are a gorilla without breasts

Andrea: Oooh bitchy hating on me, if you're gonna hate then hate on something that's true;) The only 'fault' I have, is that I have small breasts for my age. That is the only thing that people can hate on. Come up with something new, this is getting old.

Andrea frequently addressed hate of this kind and expressed that she received a lot of hate as direct messages. She thereby acknowledged her presence in this space as being imbued with a constancy of hate. The position she took in relation to such hate was to dismiss it as either untrue, or as the result of jealousy. Her responses were often cheeky and ironic in their wording. In this way, she adopts a strategy of humour and affective distancing, demonstrating that she was unperturbed by the hate. Her use of the winky-face above is such an example of distancing. She thereby recognized that sexualized and gendered hate as inevitable in this space, but that it did not affect her. Andrea, however, recognized that she had "small breasts for her age" and that this was something "that people [could] hate on". She thus distanced herself from this bodily target of hate by recognizing and appropriating it, all the while also recognizing that if you had small breasts for your age then you would likely receive hate. In this sense, the temporalized-bodily target of hate exists outside of Andrea's body, an object which is coded with meaning and circulated, and has thus become part of the sites "time-memory" (Clough 2012,p. 25). Sofia, in contrast to Andrea, was frequently targeted for having large breasts, considered "too big for her age", and that she should not "flaunt" them too much, because it is "slutty". Further, her sexual experience was often targeted and she was frequently called a whore or slut, as being sexually active was also identified by haters as age-inappropriate (Sylwander and Gottzén 2019). In the following example an anonymous peer reacted to sexualized hate that Sofia had received:

Anonymous: I'm freaking out on all these people hating on Sofia. Firstly she is really beautiful. It isn't her fault that she was born with big breasts. Let her look like 20 if that's what you think anyway if you don't like it then leave her page. And no one should care if she has had sex or not. Let her have a private life!!

Big breasts were thus coded as adult-like ("let her look like 20"), sexual and therefore age inappropriate (see Renold and Ringrose 2013; Ringrose and Harvey 2015; Ringrose et al. 2013; Springgay and Freedman, 2010). This coding of bodily female attributes (breasts that are too small; breasts that are too big) and the affective practices surrounding them constantly threatened to draw hate towards these girls. Girls who developed early therefore risked being targeted as "slutty" or as promiscuous, as they were seen as "too" sexual. The figure of the whore was thereby a manner to read bodies that did not strictly conform to expectations of chrononormativity (Sylwander and Gottzén 2019). Even though such a looming sense of threat could risk limiting these girls, various "lines of flight" (Deleuze and Guattari 1987) ensued following the iteration of hate. Andrea's various strategies to distance herself from the hate meant that the hate did not manage to stick to her. In both Andrea and Sofia's cases hate meant that peers came to their aid and supported them, and introduced alternative feelings and emotions to tie to their bodies.

The users frequently engaged in rating each other in accordance with "hot/not hot" scales. These scales were, among other things, codified through systems of branding, usually clothing brands, where certain brands were classed as better than others. Thereby making reading such rating systems difficult for outsiders. Most, however, were based on "fuckability," "hotness" and looks more generally. Previous research has discussed the contradictory pressures that girls' face online of, on the one hand, being rewarded for sexiness through likes and positive comments, but also risking being labelled a slut if considered as showing "too much", either in terms of how they pose or dress in pictures, or if they 
frequently post selfies they may be called "attention whores" (Freeman 2010; Renold and Ringrose 2013; see also (Sylwander and Gottzén 2019). Clothing and make-up were signifiers which circulated and were drawn on to police and injure girls in chrononormative ways. The most significant of these were the g-string and the push-up bra, which were circulated as sexualized and as age-inappropriate for girls a certain age (see Renold and Ringrose 2011, 2013; Ringrose and Harvey 2015). Lisa had been targeted for wearing a g-string by multiple users for some time. A peer responded, expressing anger at this type of hate, comparing the g-string to a nonsexualized garment like "knee socks" pointing out that you would not be targeted for wearing such a garment, thus highlighting the affective and emotional significance of the $\mathrm{g}$-string by contrast. These materialities became threatening when they circulated and disciplined through the threat of hate. The g-string, as coded signifier (of inappropriateness) momentarily stuck in an intensified circulation of affect. Even when these affective intensifications occur they are temporary and they pass with varying speed. The act of hate and the hater were read by the anonymous peer as "immature cowardly 5 year old," thereby also placing certain acts outside of the chrononormative range of expected behaviour, thus feeding a sense of entitlement to retaliate (Freeman 2010). This threat of hate accumulated and reverberated over time and across (online) spaces (cf. Kuntsman 2012), as the posts remain on a user's profile, cross profiles, are hyperlinked to other users, are reiterated elsewhere, and are seen and felt by other users. These examples show how chrononormative understandings of bodies, things, and practices were felt by users, as disgusting, worthy of hate, as desirable (sexy) and as inappropriate. The accumulation of these emotions as well as the expectations that repeated targeting and recurring cycles of hate bring about, create an atmosphere of constant risk among these users, which I understand specifically as an atmosphere of sexualized hate.

\section{Anonymous Cowards and the Embodied Threat of Anonymity}

As a fair body of research has already suggested (e.g. Chui 2014; Keipi 2018; Rösner and Krämer 2016), anonymity produces an asymmetry between users, where perpetrators of hate may become less inhibited and may express stronger opinions or more hateful language than they otherwise would have offline in a face-to-face encounter. Previous research has also suggested that most hate online is posted anonymously, or through unidentifiable pseudonyms, so too is the case in this study (Brown 2018; Gagliardone et al. 2015). Users, and particularly targets of hate, expressed the way in which the constant threat of hate affected them, the feelings this evoked about themselves, as well as the feelings it evoked about those that perpetrated this hate. Anonymity and the hate perpetrated through anonymity-produced feelings of sadness, vulnerability, exposure, disgust and (very importantly) anger, among users.

The following example is an exchange that followed an emotionally charged post by an anonymous girl who was angry at Sara for allegedly stealing her romantic interest, saying that this destroyed her life, using a plethora of gendered sexualized slurs.

Anonymous: I hope you die

Sara: Now you really need to quit. God it's so immature, I can't even deal with people like you. Is there any reason for you to hate on me have I ever done anything against you? How am I going to find out what happened and fix things if I don't know who you are, you anonymous coward. Things like this make people commit suicide etc things that you have written to me even though I haven't posted and you send me like 10 messages in one minute so I know it must be the same person writing, just grow up and get a life.

Sara's response exemplifies the asymmetry that she experienced as a result of being intensively targeted by this anonymous user. She expressed feeling that she was unsure of the reason behind the hate, and being powerless to change or rectify the problem (to "fix things"). She described the hater as an anonymous coward and as immature and as not having a life ("just grow up and get a life"), pointing to the potentially dangerous implications that such hate can have ("people commit suicide"). She wrote that she had been receiving direct messages "like 10 messages in one minute" that were anonymous but that she assumed were from the same sender due to their temporal proximity. This indicates how for Sara the atmosphere changed and became unbearable through this intensification. This also points to the different layers of interaction and the directionality of affect related to anonymity. Here, hate had been communicated through direct messaging, and the intensity of those messages affected how Sara felt when she logged into the SNS. This fear was accompanied by the uncertainty "of not knowing where the accusations or threats [were] coming from," which in turn seemed to intensify "the affects and language involved" (Kofoed 2014, p. 176). However, this was not visible on her profile and therefore only became visible once she had posted publicly about it (it was thus "written into being"). This could thereby be felt by peers visiting her profile once Sara had acknowledged and narrated the extent of the assault.

The possibility of anonymity on this SNS added a specific dimension to the interaction. boyd (2010) points out that context collapses can occur on public SNSs as a result of invisible and undefined audiences. This can bring different normative contexts to collide and create very "tricky social situations". Kofoed also talks about collapse but in regard to the noncontinuity between one's self-perception and others' perception of oneself, as a collapse of "affective continuity" (Kofoed 2014, 
p. 176). Anonymity seemed to heighten expectations of being targeted by injurious acts among these users. When such anonymous threats materialized in blatantly overt, as well as more covert, ways, they were understood as injurious, "violent, offensive and/or threatening" (p. 176). This specific atmosphere of hate was thus closely related to the perception of the role of anonymity in allowing the transmission of hateful content. Emelie who expressed that she received a lot of anonymous hate posted the following: "At least I am not sitting and writing anonymously! You are the most disgusting person ever you piece of shit, get out of here." This exemplifies how an imagined anonymous hater was perceived as disgusting and as deserving of counter-aggression. Another wrote, "You writing hate to Andrea you are just really fkn childish. You would never dare to say those things to her f2f [face-to-face] you would just chicken out and walk away. Really immature people that hang out here." Andrea herself described in a post how "NO SANE person would sit here and hate on people", pointing out that haters probably were mentally unwell. The users tied certain feelings and affects to the figure of an anonymous immature "hater", one who engaged in hate with the intention to hurt, to create drama or to spread lies, and lastly a coward hiding behind a screen too afraid to say "it" face-to-face. The infantilization and pathologizing of the imagined hater as immature and mentally unwell reflected the act of hate as morally reprehensible and as "a-normative" (Cook et al. 2016). The anonymous hater was in this manner fixed as the cause of the tension and thus the atmosphere of hate (Ahmed, 2004/2014). This together with the context collapse (boyd 2010; Marwick and boyd 2011) such a perceived attack represented, seemed to intensify the sense of entitlement to retaliate through an emotionally charged act of defence (Freeman 2010). The figure of the immature, cowardly hater without a life, as "a-normative" and as breaching chrononormative expectations on behaviour, all seemed to feed into a shared sense of ever threatening hate, much like how Phillips describes popular understandings of anonymous online trolls (Phillips 2015). The collective understandings reflected in shared articulations concerning the emotions that anonymous haters produced were both exerted by the atmosphere on the platform, as they were circulated as affective practices (cf. Anderson 2009; Anderson and Ash 2015). But the users articulating these feelings were also exerting back into the online atmosphere contributing to the production of a collective sense and feeling of the other - the immature, cowardly hater who was intentionally hurting and "destroying" the fun.

\section{The Affective Circularity of Sexualized Hate}

The circulation of mean, aggressive and hateful content occurred in many different ways simultaneously and passing through different forms of intimacy and proximity to the users in this study. The anonymized circulation of links to hate-pages encouraged users to spread hate, and contributed to an atmosphere of hate. These hate pages usually concerned semifamous social media personalities (i.e. not famous outside of this particular SNS and among a limited number of users) and would mostly be worded in such a way that the person about who the hate page was made, "deserved" it. An example was a post sharing a link to a hate page saying that "he is so fat" "hate on him" concerning a semi famous user who the profile owner did not know personally. Another was directed at a girl for "acting like a whore! Check it out yourself" concerning a girl that the he knew, where he responded, "Actually she isn't acting like a whore, stop hating what the hell". The circulation of these kinds of links and encouragement to actively seek out particular users to target them with hate, was almost univocally met with rebuke from the profile owners, claiming that such things were unacceptable or mean. However, the sharing of the links and the hyperlinking from profiles through them meant that they nonetheless remained in circulation.

In cases where targets of hate identified as victims, the atmosphere on their profile page was coloured by how they addressed and wrote into being their own victimhood (boyd 2006). Showing vulnerability seemed to fuel and worsen the intensity of the hate received, but also the intensity of peers' responses (see Phillips 2015). Freja describes receiving a lot of hate online and that it has deeply affected her mental health. She responds to many of these hate posts. In the following exchanges, the anonymous hate posts express various levels of intensity and direct aggression.

Anonymous: Can you remove a little bit of make-up from your face I want to see how you look...it's just a bit too much sweety

Freja: this is typically one of those hate posts that make it sound like it's not hate but it is, just because you include hearts or say that you don't mean anything by it it's still hate..Stop playing

Anonymous: Shut up man your face is a whore, you go around saying that you get a lot of hate, when you are the one hating st Hahahahh stone welll

Freja: Learn how to spell, I get hate \& you don't even know anything about it so close your fat disgusting whore mouth cause it smells like jealousy

Anonymous: Are you a (Swe: fjortis) ${ }^{5}$ ? Just a question \#Nohate

Freja: is your mom a whore? Just a question \#nohate Anonymous: Good that you removed your fake lashes they were horrible

Freja: I just removed them today you WHORE CHILD (Swe: horunge)

\footnotetext{
${ }^{5}$ Fjortis is a derogatory term that is usually used to describe young teens as immature and trashy.
} 
Anonymous: YOU NEED TO REALIZE THAT YOUR EYELASHES ARE REALLY UGLY!! DON'T USE SUCH UGLY FAKE LASHES

Freja: No one asked for your opinion

Anonymous: You are really embarrassing, eww your lashes are fucking spiders legs. Don't say anything nerdy like 'don't be anonymous blab la bla' I don't have an account bitch $\odot$ ew your lashes are really sticky and gross Freja: you are laughing now, I wonder who is going to laugh when I have reported you to the police \& looked you up. Then I don't think you would be so tough WHORECHILD

Freja was targeted daily for how she applies her make-up, criticizing her for wearing "too much make-up", mascara and fake lashes in particular. She was called sexualized epithets such as "whore" and names related to affective states such as "disgusting" but also called out for being immature or a "fjortis." Fjortis refers to the age 14, but is a general derogatory term that berates a person as immature, childish, and failing to appear more mature than their age. In these exchanges Freja's responses demonstrate her perception of hate, as including acts that were felt as underhanded meanness such as her responses to messages that were written with seemingly sweet and soft words and emojis, but that nonetheless were felt as aggression ("this is typically one of those hate posts that make it sound like it's not hate but it is"). Even though Freja was frequently targeted she was also accused of being the one "hating" ("you go around saying that you get a lot of hate, when you are the one hating"). To this, Freja responds with anger "you don't even know anything about it so close your fat disgusting whore mouth cause it smells like jealousy", adopting flaming language such as sexualized feminine epithets as whore, in return. Throughout the exchanges the language and affective states used by both attackers and Freja intensifies and finally Freja says that she is going to report the haters to the police. In the exchange materialities such as make-up, fake eye-lashes, heart emojis and sexualized epithets are circulated with increasing intensity, accumulating meaning, emotion, and aggression.

In Freja's case she, defended herself actively and intensely; however, she also received a lot of supportive posts and comments, which were directed to protect her. These kinds of peer reactions were very common when someone was frequently targeted. These peer responses could at times be counteraggressive and adopt flaming language in response to perceived hate, as shown in the following example:

DON'T GIVE A SHIT ABOUT WHAT ALL THESE FKN CUNTS ARE WRITING TO YOU! THEY ARE JUST BEING CUNTS WITH NO BRAINS! I COULD FUCKING GO UP TO THEM AND MESS THEM UP!!! I'M FKN GONNA REPORT THEM TO THE
POLICE SOON!!! FUCKING LITTLE CUNTS!

GETS ME SO MAD!!!! You are really wonderful

Alice, you have the perfect looks!

A hypothetical "real life" scenario is depicted in which the respondent imagines retaliation through physical violence by "messing them up." The imagined perpetrators are here labelled as "cunts" and as "not having a brain". Sexualized insults, such as "cunt" and "whore," "are not innocent pronouncements, but are affective terms which hold the power to (hetero)sexually subjectify" (Kofoed and Ringrose 2012, p. 21; see also Sylwander and Gottzén 2019). These types of derogatory terms were the most common language adopted by peers in counter-aggressive responses. The intensive circulation of aggressive and hostile language was therefore essentially misogynistic, homophobic and adopting feminized derogatory epithets to shame and threaten, no matter if the target, hater or peer, was male or female. These were often paired with infantilizing words, such as in the exchange above, where Freja and her attackers both adopt the term whorechild (Swe: horunge). These kinds of exchanges reflect the multiple affective flows, through acts of aggression and counter-aggression, where hate circulates and intensifies through its circulation. An example of this intensification was Zoe who wrote on Andrea's profile expressing how it made her feel to read all the hate that Andrea received:

Zoe: PEOPLE WRITING HATE EVERYWHERE! DON'T YOU HAVE BETTER THINGS TO DO? IMEAN WHAT THE HELL DO YOU THINK IT IS FKN FUNNY, NO I DON'T THINK SO. THIS IS SUPPOSED TO BE A FUN APP BUT HATERS ARE DESTROYING IT MORE AND MORE WITH EVERY PASSING DAY. Damnit I puke on todays society (Zoe)

Zoe expresses a clash of atmospheric expectations between a "fun app" which is being "destroyed" by haters. She also points to a perceived difference in "point of entry" (see Ahmed 2010) into this space: "I MEAN WHAT THE HELL DO YOU THINK IT IS FKN FUNNY, NO I DON'T THINK SO". This expresses an asymmetry, where a hater perpetrates hate because it is "funny" and because "they don't have anything better to do", whereas the target and others reading the hate feel it is destructive and contributing to an increasingly hostile atmosphere: "HATERS ARE DESTROYING IT MORE AND MORE WITH EVERY PASSING DAY."

Anis is a popular boy who has a large following and users often comment on his social media "fame". He often posts selfies and quite frequently shirtless selfies at the gym or at home. He receives a lot of positive comments about his looks, his clothes and his body. However, at times he becomes 
bombarded with homophobic and heteronormative posts saying that "he looks like a girl," or that he is "extremely feminine" and suggesting that he should "change his gender" and trying to get him to "admit" that he is a "fag." He selfidentifies as heterosexual and often seems not to be offended, but rather laughs the hate off, suggesting that he benefits from the attention that this intensification brings as "haters make me famous". Anis was an example of a boy who, similarly to girls, received a lot of hateful comments, was targeted for being too visible or "showing too much." However, he managed to distance himself from the hate through irony, humour and referring to how also bad exposure was good in the sense that it increased his following and his online fame: \#hatersmakemefamous.

These examples show how hate accumulated and intensified on these users' profiles, often leading to the heightening of affect and aggressiveness, where sexualized epithets, and chrononormative materialities, such as make-up, push-up bras and g-strings, were intensely and anonymously circulated through direct messages, through hyperlinking, and through the creation of anonymous hate pages which were actively shared. Peer reactions and targets' responses further show how retaliatory acts increased and intensified an atmosphere of hate through the recirculation of sexualized hate. However, examples like Anis show how such circulation can be "muffled" (Kuntsman 2012) and alternative narratives and atmospheres evolve, where in his case, he expresses drawing "fame" from the attention hate brings to his profile.

\section{Atmospheric Shift and Troubling the Role of the Hater}

The role of being the target and victim of hate is troubled and contested in discussions concerning Andrea, Anna and Elin. On Elin's profile, an anonymous user questions Elin's claims that her and her friends (Anna and Andrea) are the victims of hate on the SNS. Anonymous here claims that Andrea, Anna and Elin have "changed" and earlier in the exchange, the groups' own actions and posts have been questioned and called out as hate.

Anonymous: You and Andrea Anna have become really mean I've been following all of you since january and you guys have changed

Elin: No, we just treat people the way they treat us. If you write stuff to us with = respect, then don't expect us to show respect or be nice back. We are exactly the same people that we were then, but we got tired of being judged anonymously after we for example try alcohol and tobacco. When I went out and had tried smoking, oh lord everyone flipped out? "You don't deserve Andrea",
"I liked you until I found out", "Ewh you are just playing cool but it's dangerous don't do it". Seriously? Am I a bad person just because I tried smoking? And it doesn't make Andrea a worse person just because she tried alcohol? Or that we use g-strings? You don't know us, and yet you claim that we have changed. Sure, we can be a bit mean sometimes. BUT that is only when you act like a bunch of dickheads towards us? Both Anna and Andrea are two wonderful people, and if they aren't nice to you need to think about why. Because our attitude depends on who you are and what you say and do while your personality is who you are yourself? And none of our personalities has changed, only our attitude toward little brats [Swe: snorungar] that are playing big behind the screen

Elin describes a shift in atmosphere that the girls experienced on the SNS and other online platforms (see Anderson and Ash 2015). She links this shift to their venturing into new experiences such as trying alcohol and tobacco, describing how "everyone flipped out" when she had tried tobacco. She further details how affective shifts have occurred in relation to the visibility of these ventures online, that people have said that they do not like her anymore, or that she does not deserve to be friends with Andrea (who is a very popular girl). She describes the perception of the girls as mean as being the result of their reacting to being treated with a lack of respect; being judged anonymously and others being a bunch of "dickheads" towards them. She ascertains that the change in atmosphere (here understood as the sense that other users get when they visit their profiles) is not a change in their personalities but rather in the way they are treated by others resulting in them needing to be more aggressive. This illustrates how atmosphere is both felt but also how it produces affect in users that are exerted back, here in the form of a sense of needing to be more aggressive when they sensed this shift, thus playing into this shift and intensifying it. She thereby justifies the increased aggressiveness from the girls by the intensity of the hate that they have received, thus as a form of self-defence and necessary resistance. Elin's description further reflects how felt atmosphere is closely related to the ways in which the girls are monitored through affective regimes of hetero- and chrononormativity, where testing alcohol and tobacco, or wearing perceived sexualized garments such as g-strings, produce emotions in peers and followers, that justifies negative feelings and hate towards the girls. These affects then circulated back to the girls and in turn intensified their sense of threat and the aggression that they, in turn, engage in.

Self-defence and counter-aggression could thereby intensify the flow of directed hate and anonymous hate through the circulation of gendered and sexualized signifiers as worthy of hate. However, hate did not only elicit negative and counteraggressive reactions; peers also reacted through expressions of 
love and direct support towards targets of hate that served to muffle or cut off the flow of hate.

\section{Passionate Friendship}

Social media is a taken for granted and necessary space for interaction among Swedish teens today. As previously mentioned, teens report that there are online environments where aggression is considered normal and demeaning language is recognized as a common form of communication (Friends 2017). Even though hate was clearly recognized as a common veryday occurrence, it was nonetheless viewed as problematic (see also Cook et al. 2016). I found that peers and friends were active supporters when someone was targeted by hate. They would thus react through a range of emotionally charged strategies of love and support. These kinds of responses by peers drew on the moral advantage they identified themselves as having over "disgusting", "cowardly" and "immature" anonymous haters. Responses of support and love muted and ruptured the flow of hate in terms of intensity. However, these acts could also add to the sense of victimization (see also Phillips 2015). Furthermore, I will examine how these flows of passionate friendship troubled, and also consolidated, hetero-chrononormative assumptions that continued to circulate through the atmosphere. Louise was frequently the target of gendered and sexualized hate, mostly for the way she dressed and did her make-up.

Anonymous 1: Louise I barely know you but you seem like a really strong and wonderful person. Sure you wear a lot of make-up but who the fuck cares, lots of people do? You are just as cute as they are and nothing that you haters have to complain about.

Louise: don't write anonymously

Anonymous 2: You really don't deserve any hate! You are the nicest girl in the world and you probably have the loveliest heart! I don't know you but I would love to get to know a person like you! STAY STRONG!

Raniroberto: Hey, I've seen you in school several times. I definitely don't think you deserve all the hate that you get! Why the fk should anybody hate on someone as nice on both the outside and the inside as you are? stupid idiots doing that! They can go to hell. Even if I don't know you so well I'm here for you $\vee$ Staystrong Anonymous 3: I don't get why people are trying to make you feel bad its sick how jealous people are of you you are worth more than anyone can write, I can see that you aren't offended but you still don't deserve all the hate you're getting<3 \#staystrong\#stophate
Online spaces may be seen as digital archives where emotions and feelings accumulate through affective practices over time (Kuntsman 2012; Pybus 2015). The above exchanges indicate how certain affective practices and emotional scripts became circulated and popularized through, for example, hashtagging and positive mottos such as \#stophate and \#staystrong. These accumulated reiterations were linked through hashtagging and hyperlinking between profiles and thus visible as a common strategy to counter a hateful atmosphere. They expressed positive reinforcement and rejection of the claims of the haters, positioning the haters as jealous and the hate as undeserved. The posts seemed to be written by users within varying proximity to Louise, such as Rani who expresses that she did not know Louise all that well, or anonymous 2 who also expresses "not knowing [her] that well". Even though Louise's profile had a lot of hateful comments, there were nonetheless more comments of support and love, thus counter-balancing the negative atmosphere produced by the hate and counteraggression posted by friends. However, these positive comments of support nonetheless also worked to reproduce a narrative and atmospheric sense that Louise was being victimized. Here, anonymity afforded peers with varying proximity to Louise to engage in supporting and defending her. This feeds into the perspective presented by Keipi (2018), that anonymity, although being a tool that may increase negative practices, may also have a liberating effect in enabling the "forging of new friendships" (p. 99).

As users were able to edit their profiles walls, they could edit what other users saw on their profiles, and therefore the accumulation of positive and negative voices could be administered by the profile owner. In the following example Johanna expresses how Mia is strong for dealing with so much hate, and how her publishing them on her profile wall is brave and an act of resistance (dare to stand up for who you are).

Johanna: When I scroll down, I see so many HATERS comments, I can't believe that you have the energy to deal with this mia you are so damn strong!!! and that you publish them is really touching, so damn brave you dare to stand up for who you are! and I think that's good, continue that way $\vee / /$ Johanna Johanna

Johanna's sense of Mia's page is that there were many "HATERS comments" and expresses a sense of this as draining, as it must take "energy to deal with". The sense of Mia's profile that she reflects is that it nonetheless expresses a feeling of bravery and self-empowerment. This post from Johanna, left on Mia's profile, thereby strengthened this narrative and visually acted as a counterbalance to the negative and derogatory words that others had posted. 
I have discussed how negative comments concerning girls' bodies circulated with ease; however, peers would also frequently write positive comments about users who were targeted by hate. Maja had expressed that she was badly affected by hate, specifically fat-shaming, and that she had had thoughts of suicide. A peer posts the following in response to this:

Oooh maja, love your eyes, your hair, your smile, your body!! So wonderful, never commit suicide! It is just jealous haters writing hate. You are so fucking perfect. You are so fucking beautiful, your body is perfect! You are not fat! $<33333333333$ you are the best $\boldsymbol{~}$

Hanna similarly was fat shamed but received many supportive comments telling her she was the "prettiest girl in the world" and that she was going to be a "VS [Victoria Secret]model," tapered with heart emojis. Supporters for Hanna and Maja shower the girls with praise for their looks "fucking beautiful, your body is perfect", "you are not fat" and "you are the world's prettiest". Love and support were shown by peers using wording that denied the abjectness that hateful comments were imposing on users such as Hanna and Maja. However, these did not necessarily challenge the chrononormative expectations on the female body, nor the idealized forms of femininity that circulated such as the ideal of looking like a VS model and having the "perfect body". These gendered materialities thereby continued to circulate relatively untroubled. Even so, the accumulation of these positive and reinforcing posts by peers and friends, meant that the profiles belonging to users who were frequently targeted by hate could become dominated by positive comments, thus shifting the atmosphere to one dominated by positivity, friendship and love. For Johanna, Mia, Hanna, and Louise, this made their online presence bearable, although they were frequently targeted by hate.

\section{Discussion}

In my analysis I have illustrated how atmospheres of sexualized hate permeated this online space, but was also, nonetheless, constantly resisted, troubled and counterbalanced by other atmospheres such as love and friendship. Affect intensified in exchanges that surrounded the naming of hate among these young users. I have demonstrated how the users framed hate in their interaction as comments or content that was posted and/or otherwise circulated, and understood as deliberately mean. This included everything from direct aggression such as targeted insulting, hateful or vitriolic language; as being bombarded by direct messages containing mean or insulting content; and spreading rumours (particularly about users' sexual activity, promiscuity or romantic interests). As well as less obvious or indirect meanness, such as writing seemingly positive or sweet posts which included emojis such as hearts or smileys, but that were nonetheless read as trying to spread gossip, drama or being an underhanded insult. Hate seemed to be primarily directed towards girls in this context, through sexualized, gendered and aged signifiers such as breasts (big breasts/small breasts), make-up and g-strings, which were imbued with affective states and emotions such as disgust and fear. In this sense, bodies identified as female, entered this space from a specific "point of entry" (Ahmed 2010), where hate risked targeting and sticking to them more easily than bodies identified as boys. Chrononormative affective regimes thus disciplined through an atmosphere of omnipresent risk, a risk which materialized more frequently and more systematically for some such as Freja. Materialities such as bodyparts, clothing and makeup thus circulate anonymously through the online atmosphere and work to affectively discipline users. Emotions and feelings such as anger, desire and disgust are tied to these materialities, thus imbuing them with affective potential. The accumulation over time of these affective perceptabilities increased the potential for such intensity to ensue. Hate intensified affective states, but in different ways. The examples discussed above show not only how hate produced reactions of counter-aggression, thus increasing intensities, but also how expressions of love and support could work to disrupt hate and rather work to accumulate positive emotions. Hate thus served to trigger and spur on further hate, nonetheless it offered peers and targets the opportunities to resist hate. The naming and articulation of hate thereby conversely enabled an atmosphere of passionate defence and friendship, which dominated the profiles of those targeted by hate. As most of such support was posted anonymously, this troubles the idea of anonymity as a purely negative affordance.

Sundén and Paasonen (2018) discuss the affective dynamic of fear and shame in online hate, and point to how these impact bodies and move them differently, and that these directions may be surprising. Explaining how targets can both act as expected or in line with the fear and shame that the hate intends to inflict, or may well be laughed away and not produce the desired negative or limiting effect. Peers in this study have showed how they affectively turn the shame directed at targets of hate back towards the hater or simply direct the shame back towards the object of shame, as an anonymous circulating object, such as the figure of the whore or the materiality of make-up and gstrings. The affective counter-practices, however, seem to appropriate the same language, gendered derogatory terms (such as whore) and feelings (such as disgust) as they are directing their counter-aggression against in the first place. In this way, such acts of counter-aggression accumulatively work to recirculate sexualized and gendered hate, even when the purpose is to support a peer. Sundén and Paasonen (2018) also show how feminists reappropriated hateful terminology to resist gendered hate, as a subaltern strategy and source of empowerment. In the examples discussed in thi study, passionate declarations 
of love on the one the one hand serve to disrupt the intensity of the circulation of hate and associated emotions, such as disgust and anger. Thereby the accumulation of such voices of love also work to materially shift the atmosphere towards one dominated by a sense of peer-hood, thereby opening up for possibilities of resistance. Affordances, such as hyperlinking, anonymity, and online discursive practices such as hashtagging and the use of emojis such as hearts and smileys, were recruited in this intensification of positive affect through a kind of lovebombing.

Thus, this study reveals how sexualized hate circulates and is reproduced through counter-aggressive responses to hate. I therefore point to the normative and affective work involved in producing online atmospheres, where contention and aggression is intrinsic to the process of subjectification and identification in the online context. This illuminates how such processes contribute to constructing the "affective fabric" of mediated interaction and thereby also the experiences of young social media users in these contexts (Ahmed, 2004; Kuntsman, 2015). These young users expressed that they perceived this particular online space as being imbued with a constancy of hate, and thus that gendered and sexualized hate was seen as a normal aspect of interaction there, but it was nonetheless vehemently rejected, in other words "tolerated, but not encouraged" (Cook et al. 2016, p. 3337). Drawing on the important body of research within this field, as well as youths' own voiced concerns, I argue that the normative (based on gender/ethnicity/sexuality and class) and social dynamic underpinning the sense of justification to commit hurtful acts online, as well as offline, is central to understanding how peer-to-peer violence works.

Applying the concept of affective atmospheres has enabled me to discuss how the online space is felt by the users, and how this impacts their own affective capacities thereon. Theorizing atmosphere in the online context has also enabled and exploration of both the pervasiveness and ephemerality of sexualized hate in this context as an ever-present threat that materializes for some, but not for others. The materialization of hate through direct targeting can be intensified by a sense of justified counter-aggression which draws on the idea of the "hater" as immature, disgusting and intentionally wanting to cause harm. Even though this study has focused on mostly negative affect online, it also highlights how peer support and friendship evolve in these interactions. This suggests that multiple atmospheres can be present at the same time and that certain atmospheres may temporarily become dominant. So, even though users expressed an awareness of a constant threat of hate, for most users in this study, their everyday experiences were not dominated by hate, and were thus, bearable.

Furthermore, I have also shown how atmospheres relate to mainstream norms and practices of gendered policing that pass far beyond the interaction between specific users. The interactions suggest that very early on in their online experiences, users become imbricated into everyday affective practices of aggressive online culture. Further research would thus do well to look more closely at aggressive online culture more broadly when analysing youths' engagement or exposure to hurtful online behaviour.

Finally, one of the aims of this study was to contribute to research on cyberbullying and bullying more broadly by applying the theoretical concept of affective atmosphere to explore youths' experiences of aggressive practices in the online context. As there is significant interest in school climate (Hinduja and Patchin 2011, 2014) within the filed of bullying research, I suggest that affective atmosphere can contribute theoretical tools to explore both school and online atmospheres where violence occurs, in order to understand these practices outside the individualized models of bullying. Affective atmosphere in the school context can contribute to studying material and human interaction when trying to understand how the school as a physical and social space is felt and experienced. This approach could yield practical insight into matters like classroom and school space organization and design in order to prevent violence and aggression. Affective atmosphere as a concept can similarly inform platform providers about issues related to interface design and affordances, in order to promote positive social atmosphere, and to allow those that are being targeted by aggression to act effectively.

Funding Information Open access funding provided by Stockholm University. The study is part of a larger $\mathrm{PhD}$ research project which is funded by Stockholm University.

\section{Compliance with Ethical Standards}

Conflict of Interest The author declares that there is no conflict of interest.

Open Access This article is distributed under the terms of the Creative Commons Attribution 4.0 International License (http:// creativecommons.org/licenses/by/4.0/), which permits unrestricted use, distribution, and reproduction in any medium, provided you give appropriate credit to the original author(s) and the source, provide a link to the Creative Commons license, and indicate if changes were made.

\section{References}

Ahmed, S. (2004). The cultural politics of emotion. (second edition). Edinburgh: Edinburgh University Press.

Ahmed, S. (2010). The promise of happiness. Durham, NC: Duke University Press.

Anderson, B. (2009). Affective atmospheres. Emotion, Space and Society, 2(2), 77-81.

Anderson, B., \& Ash, J. (2015). Atmospheric methods. In P. Vannini (Ed.), Non-representational methodologies : Re-envisioning research. New York, NY: Routledge.

Barlett, C. P., \& Chew, C. (2016). Predicting cyberbullying from anonymity. Psychology of Popular Media Culture, 5(2), 171-180.

Boyd, D. (2006). Friends, friendsters, and myspace top 8: Writing community into being on social network sites. First Monday, 11, 12. 
Boyd, D. (2010). Social network sites as networked publics: Affordances, dynamics, and implications. In Z. Papcharissi (Ed.), A networked self (pp. 39-59). New York: Routledge.

Brown, A. (2018). What is so special about online (as compared to offline) hate speech? Ethnicities, 18(3), 297-326.

Chui, R. (2014). A multi-faceted approach to anonymity online: Examining the relations between anonymity and antisocial behaviour. Journal for Virtual Worlds Research, 7(2).

Clough, P. T. (2012). War by other means: What difference do(es) the graphic(s) make? In A. Karatsogianni \& A. Kuntsman (Eds.), Digital cultures and the politics of emotion: Feelings, affect and technological change (pp. 21-33). Basingstoke: Palgrave Macmillan.

Cook, C., Schaafsma, J., \& Antheunis, M. (2016). Under the bridge: An in-depth examination of online trolling in the gaming context. New Media \& Society, 20(9), 3323-3340.

Crooks, H. R. (2017). An intersectional feminist review of the literature on gendered cyberbullying: Digital girls. Jeunesse: Young People, Texts, Cultures, 8(2), 62-88.

Deleuze, G., \& Guattari, F. (1987). A thousand plateaus (B. Massumi, trans.). Minneapolis: University of Minnesota Press (Original Work Published 1980).

Fox, N. J., \& Alldred, P. (2015). New materialist social inquiry: Designs, methods and the research-assemblage. International Journal of Social Research Methodology, 18(4), 399-414.

Freeman, E. (2007). Introduction. GLQ: A Journal of Lesbian and Gay Studies, 13(2-3), 159-176.

Freeman, E. (2010). Time binds: Queer temporalities, queer histories. Duke University Press.

Friends. (2017). Friends nätrapport 2017. Retrieved from http://friends. se/fakta-forskning/rapporter/natrapporten/.

Friends (2018). Friendsrapporten 2018. Retrieved from http://friends.se/ fakta-forskning/rapporter/friendsrapporten/.

Gagliardone, I., Gal, D., Alves, T., \& Martinez, G. (2015). Countering online hate speech. Unesco Publishing.

Ging, D., \& Siapera, E. (2018). Special issue on online misogyny. Feminist Media Studies, 18(4), 515-524.

Gini, G., \& Pozzoli, T. (2009). Association between bullying and psychosomatic problems: A meta-analysis. Pediatrics, 123(3), 10591065.

Gottzén, L., \& Sandberg, L. (2017). Creating safe atmospheres? Children's experiences of grandparents' affective and spatial responses to domestic violence. Children's Geographies, 1-13.

Hinduja, S., \& Patchin, J. W. (2010). Bullying, cyberbullying, and suicide. Archives of Suicide Research, 14(3), 206-221.

Hinduja, S., \& Patchin, J. W. (2011). Overview of cyberbullying. White House Conference on Bullying Prevention, 21.

Hinduja, S., \& Patchin, J. W. (2012). School climate 2.0: Preventing cyberbullying and sexting one classroom at a time. Thousand Oaks, CA: Corwin Press.

Hinduja, S., \& Patchin, J. W. (2014). Cyberbullying: Identification, prevention, \& response. New York: Routledge.

Holt, M. K., Vivolo-Kantor, A. M., Polanin, J. R., Holland, K. M., DeGue, S., Matjasko, J. L., Wolfe, M., \& Reid, G. (2015). Bullying and suicidal ideation and behaviors: A meta-analysis. Pediatrics, 135(2), 496-509.

Jane, E. A. (2017). Feminist flight and fight responses to gendered cyberhate. In M. Segrave \& L. Vitis (Eds.), Gender, technology and violence (pp. 45-61). New York: Routledge.

Keipi, T. (2018). Relatedness online: An analysis of youth narratives concerning the effects of internet anonymity. Young, 26(2), 91-107.

Kofoed, J. (2014). Non-simultaneity in cyberbullying. In S. Robin May \& S. Dorte Marie (Eds.), School bullying: New theories in context.

Kofoed, J., \& Ringrose, J. (2012). Travelling and sticky affects: Exploring teens and sexualized cyberbullying through a Butlerian-
Deleuzian-Guattarian lens. Discourse: Studies in the Cultural Politics of Education, 33(1), 5-20.

Kozinets, R. V. (2015). Netnography: Redefined (Second ed.). Thousand Oaks, CA: Sage Publications.

Kuntsman, A. (2012). Introduction: Affective fabrics of digital cultures, introduction. In A. Karatsogianni \& A. Kuntsman (Eds.), Digital cultures and the politics of emotion: Feelings, affect and technological change (pp. 1-17). Basingstoke: Palgrave Macmillan.

Lambert, E. B. (1999). Do School playgrounds trigger playground bullying? Canadian Children, 24(1), 25-31.

Lapidot-Lefler, N., \& Barak, A. (2012). Effects of anonymity, invisibility, and lack of eye-contact on toxic online disinhibition. Computers in Human Behavior, 28(2), 434-443.

Lawrence, R. (1998). School crime and juvenile justice. Oxford: Oxford University Press.

Lee, S. W. (Ed.). (2005). Encyclopedia of school psychology. Thousand Oaks, CA: Sage Publications.

Livingstone, S., \& Smith, P. K. (2014). Annual research review: Harms experienced by child users of online and mobile technologies: The nature, prevalence and management of sexual and aggressive risks in the digital age. Journal of Child Psychology and Psychiatry, $55(6), 635-654$.

Loukas, A., \& Robinson, S. (2004). Examining the moderating role of perceived school climate in early adolescent adjustment. Journal of Research on Adolescence, 14(2), 209-233.

Loukas, A., Suzuki, R., \& Horton, K. D. (2006). Examining school connectedness as a mediator of school climate effects. Journal of Research on Adolescence, 16(3), 491-502.

Mantilla, K. (2013). Gendertrolling: Misogyny adapts to new media. Feminist Studies, 39(2), 563-570.

Markham, A., Buchanan, E., \& Committee, A. E. W. (2012). Ethical decision-making and internet research: Version 2.0. Association of Internet Researchers. Retrieved at: https://aoir.org/reports/ethics2. pdf.

Markham, A. N. (2013). Fieldwork in social media: What would Malinowski do? Qualitative Communication Research, 2(4), 434 446.

Marwick, A. E., \& Boyd, D. (2011). I tweet honestly, I tweet passionately: Twitter users, context collapse, and the imagined audience. New Media \& Society, 13(1), 114-133.

Massumi, B. (1995). The autonomy of affect. Cultural Critique, 31, 83109.

McInroy, L. B., \& Mishna, F. (2017). Cyberbullying on online gaming platforms for children and youth. Child and Adolescent Social Work Journal, 34(6), 597-607.

McVeigh-Schultz, J., \& Baym, N. K. (2015). Thinking of you: Vernacular affordance in the context of the microsocial relationship app, couple. Social Media+ Society, 1(2).

Moor, P. J. (2007). Conforming to the flaming norm in the online commenting situation. University of Twente. Retrieved from: http://purl.utwente.nl.essays/58838.

Moor, P. J., Heuvelman, A., \& Verleur, R. (2010). Flaming on youtube. Computers in Human Behavior, 26(6), 1536-1546.

Murthy, D. (2008). Digital ethnography: An examination of the use of new technologies for social research. Sociology, 42(5), 837-855.

Paasonen, S. (2015). A midsummer's bonfire: Affective intensities of online debate. In K. Hillis, S. Paasonen, \& M. Petit (Eds.), Networked affect (pp. 27-42). Cambridge, Mass: MIT Press.

Paasonen, S., Hillis, K., \& Petit, M. (2015). Introduction: Networks of transmission: Intensity, sensation, value. In K. Hillis, S. Paasonen, \& M. Petit (Eds.), Networked affect (pp. 1-26). Cambridge, Mass: MIT Press.

Phillips, W. (2015). This is why we can't have nice things: Mapping the relationship between online trolling and mainstream culture. Camrbidge, Mass: MIT Press. 
Pybus, J. (2015). Accumulating affect: Social networks and their archives of feelings. In K. Hillis, S. Paasonen, \& M. Petit (Eds.), Networked affect (pp. 235-250). Cambridge, Mass: MIT Press.

Renold, E., \& Ringrose, J. (2011). Schizoid subjectivities? Re-theorizing teen girls' sexual cultures in an era of 'sexualization'. Journal of Sociology, 47(4), 389-409.

Renold, E., \& Ringrose, J. (2013). Feminisms re-figuring 'sexualisation', sexuality and 'the girl'. Feminist Theory, 14(3), 247-254.

Ringrose, J., \& Harvey, L. (2015). Boobs, back-off, six packs and bits: Mediated body parts, gendered reward, and sexual shame in teens' sexting images. Continuum, 29(2), 205-217.

Ringrose, J., Harvey, L., Gill, R., \& Livingstone, S. (2013). Teen girls, sexual double standards and 'sexting': Gendered value in digital image exchange. Feminist Theory, 14(3), 305-323.

Rösner, L., \& Krämer, N. C. (2016). Verbal venting in the social web: Effects of anonymity and group norms on aggressive language use in online comments. Social Media+ Society, 2(3), 2056305116664220.

Sikhakhane, H. N., Muthukrishna, N., \& Martin, M. (2018). The geographies of bullying in a secondary school context. South African Journal of Education, 38(1).

Springgay, S., \& Freedman, D. M. (2010). Breasted bodies as pedagogies of excess. In Handbook of public pedagogy: Education and learning beyond schooling (p. 351).

Sylwander, K.R. \& Gottzén, L. (2019). Whore! Affect, sexualized aggression and resistance in young social media users' interaction. Sexualities, (Online first). DOI: https://doi.org/10.1177/ 1363460719872727

The Swedish Media Council [Swe: Statens Medieråd] (2013). Ungar \& medier 2012/13 - Barn, unga och medier [report]. Retrieved from: https://statensmedierad.se/publikationer/ungarochmedier/ ungarmedier201213.537.html.
The Swedish Media Council [Swe: Statens Medieråd] (2015). Ungar \& medier 2015: demografi - Barn, unga och medier [Report]. Retrieved from: https://statensmedierad.se/publikationer/ ungarochmedier/ungarmedier2015demografi.962.html?query= unga.

The Swedish Media Council [Swe: Statens Medieråd] (2017). Ungar \& medier 2017 - Barn, unga och medier [report]. Retrieved from: https://statensmedierad.se/publikationer/ungarochmedier/ ungarmedier2017.2344.html?query=*\&Amnesomrade=Ungar\% 20och\%20medier.

Sticca, F., \& Perren, S. (2013). Is cyberbullying worse than traditional bullying? Examining the differential roles of medium, publicity, and anonymity for the perceived severity of bullying. Journal of Youth and Adolescence, 42(5), 739-750.

Suler, J. (2004). The online disinhibition effect. Cyberpsychology \& Behavior, 7(3), 321-326.

Sundén, J., \& Paasonen, S. (2018). Shameless hags and tolerance whores: Feminist resistance and the affective circuits of online hate. Feminist Media Studies, 1-14.

Svensson, M., \& Dahlstrand, K. (2013). Kränkningar, trakasserier och hot på nätet. Delrapport till Ungdomsstyrelsen med fokus på kvantitativ kartläggning. Lund: Rättssociologiska institutionen Lunds universitet.

Todd, C. (2015). Commentary: GamerGate and resistance to the diversification of gaming culture. Women's Studies Journal, 29(1), 64.

Vaillancourt, T., Brittain, H., Bennett, L., Arnocky, S., McDougall, P., Hymel, S., Short, K., Sunderani, S., Scott, C., \& Mackenzie, M. (2010). Places to avoid: Population-based study of student reports of unsafe and high bullying areas at school. Canadian Journal of School Psychology, 25(1), 40-54. 